\title{
ZELENA INFRASTRUKTURA V PRAKSI
}

\section{Strokovno srečanje ob Mesecu prostora}

Tudi v letošnjem letu smo na Oddelku za geografijo nadaljevali s tradicijo prirejanja strokovnih srečanj ob Mesecu prostora. Leto 2018 je na prostorskem področju zaznamovala nova prostorska in gradbena zakonodaja (Zakon o urejanju prostora, Gradbeni zakon, Zakon o arhitekturni in inženirski dejavnosti). Zato je Ministrstvo za okolje in prostor za letošnjo temo Meseca prostora predlagalo slogan »Prostor je zakon«. Na Oddelku za geografijo smo z letošnjim Mesecem prostora želeli prispevati k boljšemu poznavanju in razumevanju zelene infrastrukture v praksi. Slednja ima zaradi povezanosti fizične in družbene razsežnosti velik potencial za integracijo različnih raziskovalnih usmeritev znotraj geografije in tudi povezovanja $\mathrm{z}$ drugimi strokami.

Srečanje je potekalo 10. oktobra 2018 na Oddelku za geografijo in je bilo zasnovano zelo smiselno in strukturirano, saj smo od evropskega konteksta in razumevanja zelene infrastrukture preko makro regionalnih projektov zelenih in modrih koridorjev prišli do vključenosti zelene infrastrukture v strategijo prostorskega razvoja Slovenije. Po odmoru sta sledili predstavitvi dveh različnih praktičnih primerov (evropski projekt urbanega kmetijstva v Velenju in študentski projekt priprave kolesarskih poti v Brkinih). V popoldanskem delu so študentje geografije na delavnici iskali možnosti za nadgradnjo obstoječega projekta kolesarskih poti v Brkinih.

V uvodni predstavitvi je dr. Barbara Lampič (Oddelek za geografijo FF UL) prikazala svoje izkušnje kot predstavnica Slovenije za področje Rabe prostora in prostorskega načrtovanja pri Evropski okoljski agenciji. Slednja pri obravnavi zelene infrastrukture v ospredje seveda postavlja okoljski vidik, predvsem vlogo zelene infrastrukture pri ohranjanju biotske raznovrstnosti. Spoznali smo zakonodajni okvir in časovni potek vključevanja zelene infrastrukture v evropske strategije. Ključni poudarek predstavitve pa je bil cilj ničelne neto pozidave zemljišč. Izjemnega pomena je namreč, da bi težave preprečevali in ne reševali po tem, ko nastanejo. Do tja pa nas, kot je izpostavila referentka, čaka še dolga pot.

Dr. Mitja Bricelj (Ministrstvo za okolje in prostor) je predstavil vključenost zelene infrastrukture v različne makroregionalne projekte, ki se izvajajo na območju Slovenije. Poseben poudarek je bil na vzrokih za načrtovanje zelene infrastrukture kot odgovor na obstoječe načrtovanje sive infrastrukture. Hkrati je bil izpostavljen ekosistemski pristop k načrtovanju, ki se uspešno implementira v različnih projektih. Bricelj je kritično ugotovil, da gre pri teh razmišljanjih za »tradicionalna znanja v novi preobleki« ter v ospredje postavil tudi povezavo med družboslovjem in naravoslovjem.

Ta stik je poudarila tudi dr. Nadja Penko Seidl (Oddelek za krajinsko arhitekturo BF UL), ki je sodelovala pri pripravi strokovnih podlag za Strategijo prostorskega razvoja Slovenije. Zelena infrastruktura je namreč lahko zelo dober primer pomena povezovanja in sodelovanja strokovnjakov z različnih področij, tako raziskovalnih kot načrtovalskih. 
Na podoben način bi morala zelena infrastruktura povezovati tudi naravna okolja in kulturno krajino. Koncept prostorskega razvoja Slovenije sicer opredeljuje tri ravni zelene infrastrukture: jedrna območja, ki jih predstavljajo naravno ohranjeni kompleksi, koridorji, ki služijo kot povezave med temi območji, ter stopalni kamni, ki predstavljajo naravno bolj ohranjene prostore znotraj urbanizirane ali intenzivno obdelane pokrajine. Kot pomembna se izkazuje tudi hierarhičnost obravnave zelene infrastrukture, ki se mora hkrati navezovati na višje prostorske ravni (makroregije) in nuditi izhodišča za načrtovanje na nižjih ravneh.

Prav na to raven smo se preselili po odmoru. Najprej nam je dr. Jani Kozina (Geografski inštitut Antona Melika ZRC SAZU) predstavil njihovo sodelovanje pri evropskem projektu AgriGo4Cities, kjer se ukvarjajo z urbanim kmetijstvom. Projekt skuša urbano kmetijstvo uporabiti kot orodje za participativno načrtovanje, socialno vključenost in trajnostni urbani razvoj. Vidimo torej, da je poleg okoljske funkcije zelene infrastrukture poudarjena še socialna funkcija, kar daje tem pobudam dodatno težo. Slovenski partner v projektu je Mestna občina Velenje, ki dosega zelo dobre rezultate med sodelujočimi mesti.

Zadnja predstavitev nas je popeljala z mesta na podeželje, s kmetijstva na kolo v Brkine. Predstavljen je bil projekt študentov geografije pri predmetu Regionalna neskladja na podeželju (Oddelek za geografijo FF UL), kjer so študenti pod vodstvom mentorice dr. Irme Potočnik Slavič najprej zelo dobro analizirali projektno območje in izluščili okoljski potencial kot tistega, ki ga je vredno razvijati. Poseben dosežek projekta je bila zahtevna uskladitev številnih deležnikov. Glavni rezultat projekta je kolesarska karta Brkinov, ki postaja seme povezave med občinami in drugimi deležniki v Brkinih.

Zanimive teme so odprle številna vprašanja, ki so dodatno poudarila potrebo po sodelovanju in tudi potrebo po večjem glasu stroke pri načrtovanju in v javnosti.

V popoldanski delavnici, namenjeni študentom geografije, je 25 študentov podrobneje razpravljalo o šestih vprašanjih, povezanih z zeleno infrastrukturo v Brkinih. Oblikovali so zanimive predloge, kako bi:

- izdelali mobilno aplikacijo za uporabnike kolesarske karte Brkinov,

- predstavili strukturo športnega dneva za osnovnošolce,

- zasnovali izobraževalno srečanje o zeleni infrastrukturi za prebivalce Brkinov,

- izpeljali kolesarski (pol)maraton po Brkinih,

- oblikovali kooperative ponudnikov turističnih storitev v Brkinih in

- načrtovali povezovanja brkinskih ekoloških kmetov z dogodki, povezanimi z zeleno infrastrukturo.

Delavnico sta vodili Eva Šabec (Lokalni pospeševalni center Pivka) in dr. Irma Potočnik Slavič (Oddelek za geografijo FF UL). Predlogi, ki so jih pripravili študentje, bodo posredovani deležnikom v lokalnem okolju, o njihovi potencialni izvedbi bodo študentje in Oddelek za geografijo obveščeni predvidoma ob zaključku zimskega semestra študijskega leta 2018/2019.

Za pomoč pri sodelovanju bi se v imenu organizacijskega odbora zahvalila vsem sodelujočim, še posebej pa študentom smeri Regionalno planiranje in urbano-ruralne študije. 
Zbornik povzetkov in predstavitve so dostopne na spletni strani Oddelka za geografijo: http://geo.ff.uni-lj.si/publikacije/druge_publikacije.

Nejc Bobovnik in Irma Potočnik Slavič

Udeleženci strokovnega srečanja (foto: M. Rebolj).

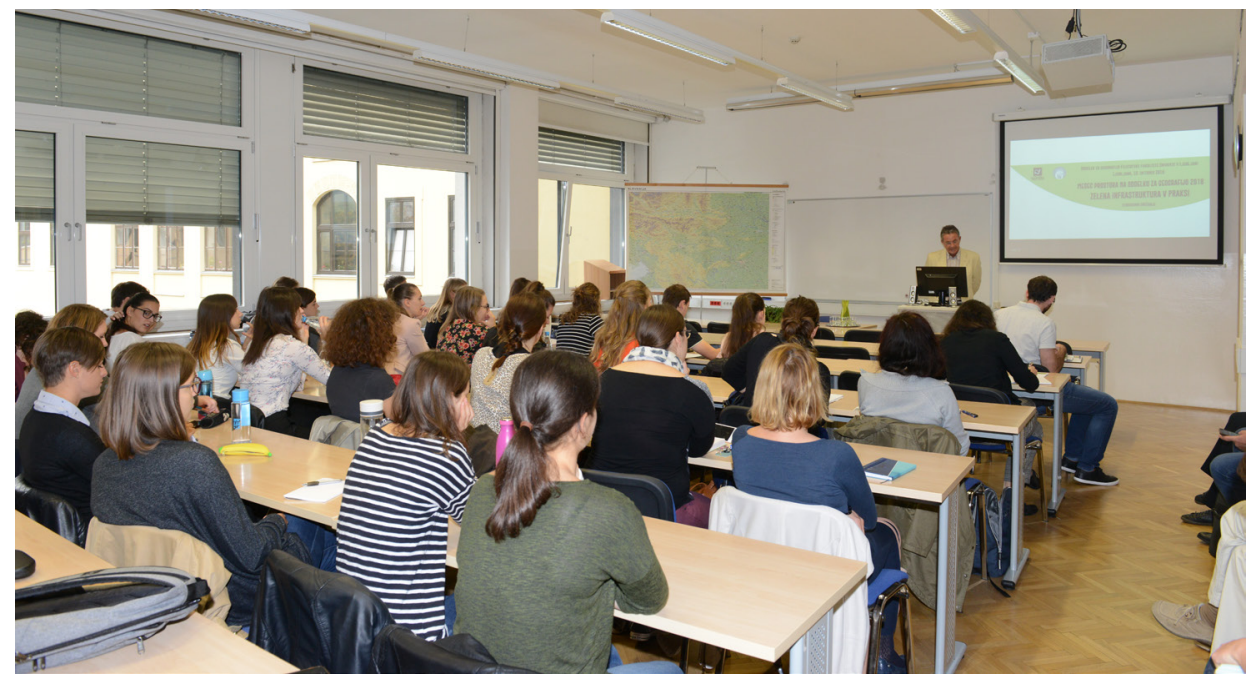

Naslovnica zbornika povzetkov.

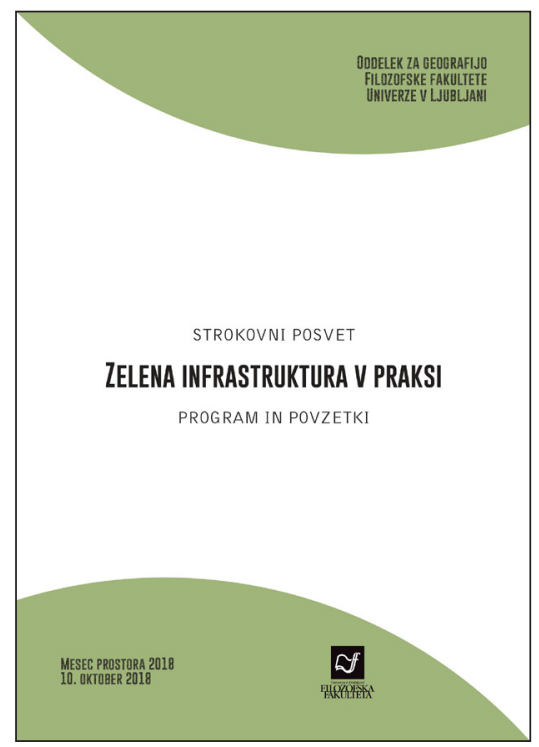

